\section{Childhood blindness in Uzbekistan}

other surveyed countries in Asia show that vitamin A deficiency and corneal scarring from measles are seen as major contributory factors in the less developed regions, whereas retinal dystrophies and microphthalmos play a more prominent role in more developed areas. Cataract is a major feature in both situations. ${ }^{2}$ The same shift has been seen in the UK over the last century as documented by Jay. ${ }^{11}$ This study set out to ascertain the causes of childhood blindness in Uzbekistan. Until these data are available, appropriate plans and interventions to tackle the problem cannot be made.

Uzbekistan is doubly land-locked (i.e. not only land-locked, but every state with which it has a border is also land-locked) in the heart of Central Asia. The central plains of the country are semi-desert, sparsely populated and separate the areas of the North West around the Aral Sea from the South East, where there is the greatest density of population in the Fergana Valley. Uzbekistan gained its independence in 1991. It has a population of 23 million of whom $71.4 \%$ are Uzbek, $8.3 \%$ Russian, $4.7 \%$ Tajik and $4.1 \%$ Kazakh. Many other ethnic groups are represented within the population, reflecting the numerous migrations, trade routes and conquests that have affected the area throughout history. ${ }^{12}$

The overall prevalence of blindness within the Republic is unknown but the locally accepted estimate of $0.5 \%$ would be in keeping with data from other parts of the world. ${ }^{13}$ The birth rate is 33.7 per thousand per annum and $43 \%$ of the population are under the age of 16 years (i.e. 9.9 million). ${ }^{14}$ The number of blind children, assuming a childhood blindness prevalence of $0.5 / 1000(1 / 10$ th the adult figure), ${ }^{2}$ is probably 5000 in the country as a whole. Assuming that the life expectancy of a blind child is little different from that of a sighted person (only $4.5 \%$ of males and $5.6 \%$ of females are over 65 years) ${ }^{14}$ and that their blindness will extend throughout the normally productive years, the economic consequences of childhood blindness are considerable.

\section{Materials and methods}

The Department of People's Education in Uzbekistan provides boarding school (Internat) places for blind and other handicapped or orphaned children in 67 institutions throughout
N.K. Rogers

C.E. Gilbert

A. Foster

International Centre for Eye Health

Institute of Ophthalmology London, UK

B.O. Zakhidov

Department of Paediatric Ophthalmology

Tashkent Medical Paediatric Institute

Tashkent, Uzbekistan

C.J. McCollum

Department of

Ophthalmology

University of Alabama,

Birmingham

Alabama, USA

Neil Rogers

Royal Hallamshire Hospital

Sheffield S10 2JF, UK

Tel: +44 (0)1142713056

Fax: +44 (0)1142713747

e-mail:

nkrogers@compuserve.com

Sponsorship (N.K.R.):

Central Sheffield University Hospitals NHS Trust;

Christoffel-Blindenmission Childhood Blindness Research Account, University College London; Lister Travelling Fellowship, Royal College of Ophthalmologists, UK; Royal Society of Medicine Travel Fellowship; Children's Eye Study Group (UK) Travel Fellowship; The Newby Trust; Chiron Pharmaceuticals Ltd; Chauvin Pharmaceuticals Ltd; Clement Clark Ltd; Keeler Ltd; Dr Solomon Software Ltd; Mercy Project - Uzbekistan Presented as a poster at the Royal College of Ophthalmologists Annual Congress, Glasgow, 1998

Received: 22 July 1998 Accepted in revised form: 23 October 1998 


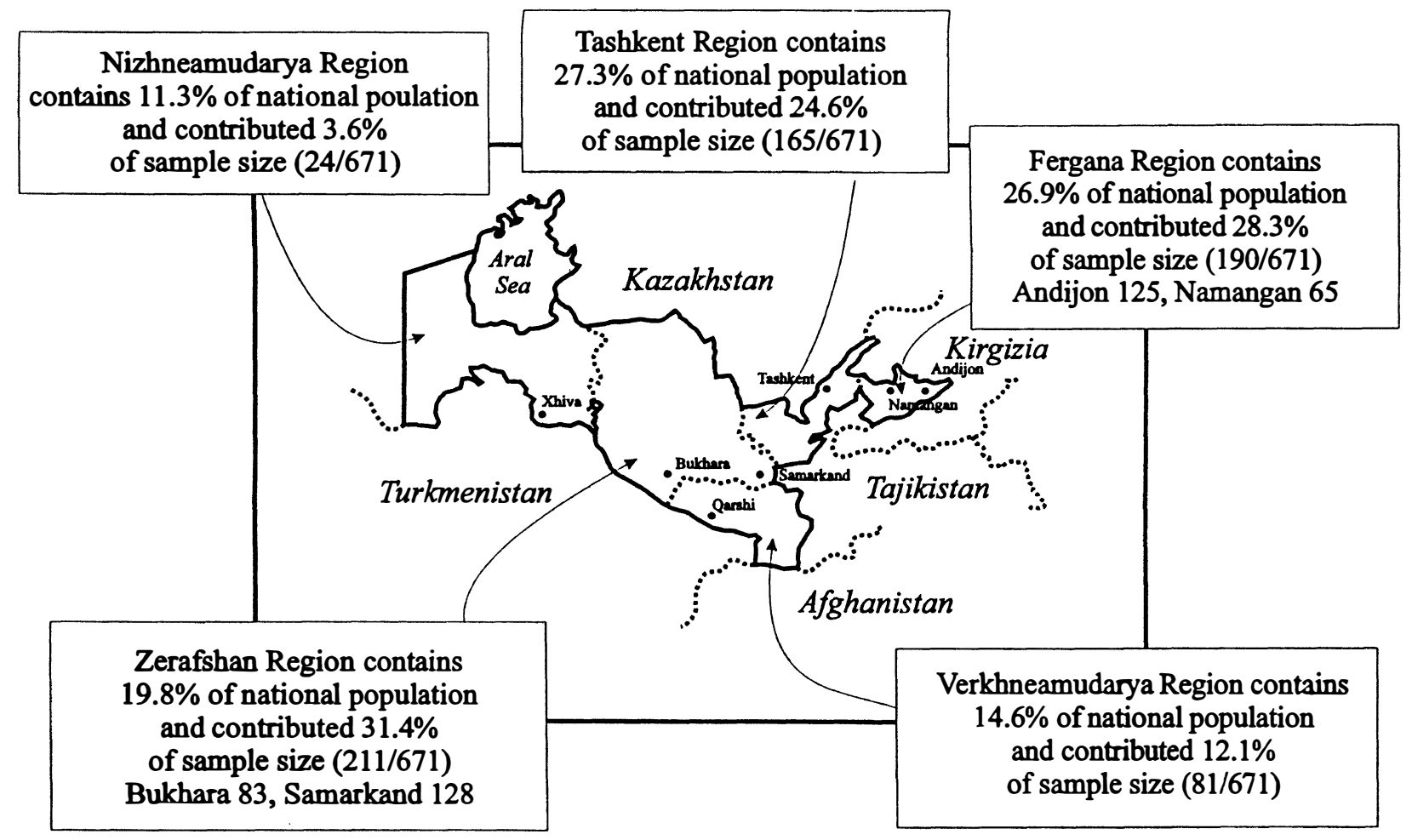

Fig. 1. Map of Uzbekistan showing the regions visited.

the country. These schools are designated as 'Blind', 'Deaf', 'Mental handicap', 'Physical handicap' and 'Multiple handicap' institutions. Precise eligibility criteria for enrolment were not available to the authors. The seven largest of these schools specifically for blind children were visited during April and May 1997. All eligible children (i.e. under 16 years of age and enrolled for visual reasons) were examined in each school.

The study was designed to give the broadest possible coverage of the centres of population in the coutry. Schools were chosen from each administrative region. Smaller schools were not visited due to limited time and resources. In each location permission to enter the schools was obtained from the local government administrative departments. The schools' directors were contacted in advance and informed of the purpose of the survey and a further briefing occurred on arrival. At the end of each visit a session was held with school staff and local medical personnel to report the findings and discuss possible options for future management.

The WHO/PBL examination form ${ }^{15}$ has been used extensively in surveys of childhood blindness. ${ }^{46}$ It is designed to give a background history for each child examined. Visual acuity was measured using a Snellen 'illiterate $\mathrm{E}^{\prime}$ chart and each child underwent initial examination with loupe spectacles and pen-torch, which indicated whether portable slit lamp, dilated fundal examination by indirect ophthalmoscopy or retinoscopy was required. The anatomical site and causative aetiology were documented and any suggested therapeutic interventions were noted so that appropriate measures could be instigated.

Data were stored on the WHO/PBL data base, ${ }^{15}$ from which frequency charts and distributions were derived.

\section{Results}

Fig. 1 shows the locations and numbers of children examined. There were 396 males (59\%) and 275 females (41\%). Nearly $10 \%$ (49) of children were under the age of 8 years, $45.5 \%$ (230) were $8-11$ years old and $45 \%$ (227) between 12 and 15 years of age. The distribution of visual acuities is shown in Table 1. Over a third of the children had undergone ophthalmic surgery (cataract 97, glaucoma 29, keratoplasty 2, enucleation 14, multiple or indeterminate 99).

Table 1. Numbers of children in each WHO category of visual loss

\begin{tabular}{lcrr}
\hline WHO category & Visual acuity & Total number & Total percentage \\
\hline No impairment & $6 / 18(20 / 60)$ or better & 34 & 5.1 \\
Visual impairment & $<6 / 18(20 / 60)$ to $6 / 60(20 / 200)$ & 127 & 18.9 \\
Severe visual impairment & $<6 / 60(20 / 200)$ to $3 / 60(10 / 200)$ & 108 & 16.1 \\
Blind & $<3 / 60(10 / 200)$ to NPL & 398 & 59.3 \\
Unable to test & & 4 & 0.6 \\
Totals & & 671 & 100 \\
\hline
\end{tabular}


Table 2. Anatomical site of major causative pathology in 506 blind and severely visually impaired children

\begin{tabular}{lcc}
\hline Anatomical site & Number & Percentage \\
\hline Whole globe & 78 & 15.4 \\
Cornea & 29 & 5.7 \\
Lens & 147 & 29.1 \\
Uvea & 28 & 5.5 \\
Retina & 153 & 30.2 \\
Glaucoma & 24 & 4.7 \\
Optic nerve & 34 & 6.7 \\
Other & 13 & 2.6 \\
\hline
\end{tabular}

Of the 506 children with blindness or severe visual impairment, the anatomical site of the major causative pathology is given in Table 2. Cataract was the major treatable pathology in 147 cases (29\%) and retinal diseases in 153 cases (30\%). Corneal scar was relatively uncommon, comprising 29 cases $(6 \%)$. The 'whole globe' category, including microphthalmos, accounted for $15 \%$ but many children with microphthalmos also had cataract. There were 126 cases of microphthalmos (23\%) in total, including a significant proportion with cataract. Twenty-five of the 126 (20\%) microphthalmics had no perception of light. The overlap between cataract and microphthalmos was such that $11 \%(56 / 506)$ of children with blindness or severe visual impairment have both diagnoses.

Of 242 eyes with unoperated cataract, 84\% (204) had a visual acuity of less than $3 / 60$ (including $11 \%$ (43) with no perception of light) and $10 \%$ (25) had an acuity of $6 / 60$ or better. In 210 aphakic eyes $65 \%$ (137) had a visual acuity of less than $3 / 60$ and $20 \%(42)$ had an acuity of $6 / 60$ or better (Table 3 ).

Among those with bilateral absence of light perception the most common cause was microphthalmos $(25 / 72=34.7 \%)$, after which retinal dystrophy comes second with $16.6 \%(12 / 72)$. Trauma, enucleations, complicated cataracts and phthisis accounted for the rest.

A regional breakdown of the three major diagnostic categories (cataract-related, retinal dystrophies and microphthalmos) is given in Table 4 . There was no significant regional difference in the distribution of these three causes, except for retinal dystrophy being less common in Nizhneamudarya Region, but the numbers in this region were too small to derive conclusions from this.

Hereditary disease (retinal dystrophies and cataract with positive family history) accounted for $54.5 \%$ of cases. Of the hereditary disease, $18 \%$ was assigned as
Table 3. Visual acuities in 242 eyes with unoperated cataract and 210 aphakic eyes

\begin{tabular}{lcccc}
\hline $\begin{array}{l}\text { Visual } \\
\text { acuity }\end{array}$ & $\begin{array}{c}\text { Unoperated } \\
\text { cataracts }\end{array}$ & Aphakia & $\begin{array}{c}\% \\
\text { cataracts }\end{array}$ & $\begin{array}{c}\% \\
\text { aphakia }\end{array}$ \\
\hline 6/6 to $6 / 18$ & 1 & 6 & 0.4 & 3 \\
$<6 / 18$ to $6 / 60$ & 24 & 36 & 10 & 17 \\
$<6 / 60$ to $3 / 60$ & 13 & 31 & 5 & 15 \\
$<3 / 60$ to PL & 161 & 126 & 67 & 60 \\
NPL & 43 & 11 & 18 & 5 \\
\hline
\end{tabular}

autosomal dominant, $57 \%$ recessive and the rest could not be determined because of insufficient pedigree information. Consanguinity was established in $33.2 \%$ of blind and severely impaired children.

Four per cent of cases were attributable to factors acquired in childhood (trauma, vitamin A deficiency, Toxocara) and only in $1.4 \%$ could intrauterine factors be definitely ascertained. However, it was noted that $18 \%$ of eyes with cataract had no perception of light, which may indicate the presence of toxoplasmosis or other undiagnosed posterior segment pathology. There was no child with retinopathy of prematurity.

The aetiology of cataract is not always straightforward to elucidate, but on the basis of family history and clinical examination it was possible to categorise $49 \%$ $(72 / 147)$ of children as having familial cataracts $(28$ dominant, 31 recessive, 13 undetermined), 44\% (65/147) of children as having sporadic cataract (43 isolated, 22 with microphthalmos) and $7 \%(10 / 177)$ as having other lens problems (e.g. ectopia lentis).

The causes of visual impairment (6/24-6/60) in 127 children are given in Table 5 . Aphakic and refractive errors accounted for $27 \%$, retinal diseases $16 \%$ and cataract $10 \%$. Spectacles for significant refractive errors (mostly aphakes) were recommended for 145 children and the provision of low vision aids for a further 226 . Of the 506 with blindness or severe visual impairment nearly half would benefit from optometric services. All 127 with visual impairment $(<6 / 18-6 / 60)$ would benefit from the provision of low vision aids. Provision of dark glasses for the 35 albinos (6 blind, 19 severe visual impairment, 10 visual impairment) is also recommended.

\section{Discussion}

There are two major sources of bias in this study. First, those children with multiple handicap or syndromes involving the eye as part of a systemic condition are

Table 4. Regional variations in the major diagnostic groups

\begin{tabular}{|c|c|c|c|}
\hline \multirow[b]{2}{*}{ Region } & \multicolumn{3}{|c|}{ Proportion of B/SVI children } \\
\hline & with cataract or aphakia & with retinal dystrophies & with microphthalmos \\
\hline Tashkent & $29.8 \% \pm 4.0 \%$ & $29.0 \% \pm 3.7 \%$ & $24.8 \% \pm 3.8 \%$ \\
\hline Fergana & $34.9 \% \pm 4.2 \%$ & $23.3 \% \pm 4.0 \%$ & $19.0 \% \pm 3.5 \%$ \\
\hline Zerafshan & $37.8 \% \pm 3.8 \%$ & $18.9 \% \pm 3.1 \%$ & $24.5 \% \pm 3.4 \%$ \\
\hline Verkneamudarya & $40.8 \% \pm 6.1 \%$ & $33.8 \% \pm 5.9 \%$ & $21.5 \% \pm 5.0 \%$ \\
\hline Nizhneamudarya & $40.9 \% \pm 10.5 \%$ & $9.1 \% \pm 6.1 \%$ & $20.5 \% \pm 8.6 \%$ \\
\hline National & $35.5 \% \pm 2.1 \%$ & $24.1 \% \pm 1.9 \%$ & $22.6 \% \pm 1.9 \%$ \\
\hline
\end{tabular}

$\mathrm{B} / \mathrm{SVI}$, blind/severely visually impaired. 
Table 5. Diagnoses of 127 children with visual impairment (visual acuity $<6 / 18$ to $6 / 60$ )

\begin{tabular}{lcc}
\hline Diagnosis & Number & Percentage \\
\hline Aphakia & 22 & $17.3 \%$ \\
Retinal dystrophy & 20 & $15.8 \%$ \\
Refractive errors & 14 & $11.0 \%$ \\
Cataract & 12 & $9.5 \%$ \\
Albinism & 10 & $7.9 \%$ \\
Others & 49 & $38.9 \%$ \\
\hline
\end{tabular}

excluded since they are educated and treated in special Internats. It was not possible to include these schools in the schedule of this survey. Thus, for example, children with congenital rubella, cortical visual impairment or retinopathy of prematurity may be significantly underrepresented in these data. There are insufficient data currently available to assess the likely magnitude of this bias. Second, the area of Karakalpakstan (semiautonomous Republic in the vicinity of the Aral Sea) was barely represented in this survey. The Aral Sea basin is an ecological, environmental and economic area quite different from all other areas of Uzbekistan. The school in Xhiva used to take children from that area and also from Turkmenistan before independence, but the small number of children examined in Xhiva is indicative of some of the difficulties faced by the region. If there are special ophthalmic conditions related to the Aral Sea area, they are not represented in this survey data set, since only six Karakalpak children were examined among the 671 .

These data indicate that there are three major diagnostic groups among the blind and severely visually impaired children in the Republic of Uzbekistan: retinal dystophies, cataract and microphthalmos. No significant problem of vitamin A deficiency was found and no evidence of retinopathy of prematurity, i.e. the distribution of aetiologies is midway between that of the economically most developed nations and that of the poorest. $^{2}$ The results are similar to those found elsewhere in Southern Asia.

The presence of children with no visual impairment as defined by the WHO usually indicated that the child had uniocular blindness (16 children), a strong family history of progressive visual loss or moderate refractive errors. Some children who were blind in one, obviously scarred, eye were more at home in a blind school than in a normal school, where they might be disadvantaged by negative attitudes of other students. The smaller number of children in the under-7 age range reflects several factors. First, is the nature of the disease process in some of the progressive retinal degenerations. Second, there are special kindergartens for children with visual problems where they receive spectacles and orthoptic supervision up to the age of 7 years, at which stage some of them graduate to the Internat schools. Third, is the issue of late presentation and diagnosis, especially in the more rural areas that still account for about $60 \%$ of the population.

\section{Cataract}

Blindness associated with cataract is usually amenable to treatment if management is instigated early enough in childhood. Nevertheless, the problems encountered in the rehabilitation process are immense. Diagnosis may not be made until well into childhood and even when made, referral for surgery may not be contemplated until later. Anaesthetic facilities for neonatal surgery are not well established and the current practice is to perform cataract surgery under ketamine sedation and retrobulbar anaesthetic, often when the child has reached school age - around 5 years old. Follow-up of these children is difficult in a setting of economic uncertainty with intermittent pharmaceutical supplies, and expensive spectacles may be beyond the means of some families. Delay of surgery beyond the age of cortical plasticity ${ }^{16-18}$ means that most of these children are densely amblyopic. High-quality aphakic spectacles or contact lenses are not currently available and the optical correction for these children is therefore suboptimal. Extracapsular techniques or lens aspiration, without posterior capsulectomy, has predisposed many of these eyes (47 of 210) to posterior capsule opacification and secclusio pupillae, some of which will proceed to secondary glaucoma.

A protocol for the management of infant cataract in the context of the developing world is being developed at the International Centre for Eye Health. The management of infantile cataract in countries with advanced economies is highly labour-intensive and costly $^{17}$ and must be adapted to situations where facilities and finance are not so freely available, if these children are to have the best achievable vision given the resources obtainable.

\section{Microphthalmos}

The proportion of blindness and severe visual impairment arising from microphthalmos in this study is similar to that found elsewhere in Southern Asia. ${ }^{4}$ There are many aetiological factors associated with microphthalmos, including a large number of hereditary syndromes, intrauterine infections and teratogenic agents. ${ }^{19}$ Elder, ${ }^{20}$ in a study of microphthalmos among Palestinian blind children, noted that among the less severely microphthalmic (7-9 $\mathrm{mm}$ corneal diameter) the aetiology of blindness was most commonly cataract or coloboma of the retina and choroid, whereas those with more severe microphthalmos (4-6 mm corneal diameter) had an unattributable aetiology of blindness but the cornea was often involved. This is in agreement with the findings in this study, in which half of those with microphthalmos have visual loss due to cataract, coloboma or corneal pathology. It is not possible from this study to attribute an aetiology to any of the cases of microphthalmos.

There were 126 children with microphthalmos (defined by a corneal diameter of $9 \mathrm{~mm}$ or less) in the study, out of 506 with blindness or severe visual 
impairment. If an extrapolation is made to the estimated 5000 blind or severely visually impaired children in the country, there may be as many as 1245 children with blinding microphthalmos in Uzbekistan out of a total estimated population of 6.6 million between the ages of 5 and 15 years. This gives an estimated prevalence of 1.9 per 10000 , which is consistent with the findings of Kallen et al. ${ }^{21}$ in a study that involved birth registries from France, Sweden and California. The work of Kallen et al. highlights the variability in reported prevalences (between 0.4 and 5.9 per 10000 ). Furthermore in Kallen et al.'s data $23 \%$ of children with microphthalmos or anophthalmos have chromosomal anomalies and 30\% have other major malformations. In the setting of Uzbekistan such children would be educated in schools for multiply handicapped children rather than blind schools, and therefore would not have been included in our study. Thus the figure of 1.9 per 10000 is almost certainly an underestimate of the true prevalence of microphthalmos in the Republic, because less severe forms of microphthalmos are not included, since they would not feature in a survey of blind schools. There does not appear to be any significant regional variation in the proportion of blind children with microphthalmos, although there are insufficient data in this study to make any conclusions with regard to the Aral Sea basin.

\section{Retinal Dystrophies}

Early-onset retinal dystrophies form the largest group of blinding diseases in this survey and although such children may benefit from low vision aids, there are no effective medical or surgical treatments available as yet. The improvement in visual function that might be experienced by some of these children by the appropriate provision of aphakic spectacles and low vision aids has to be counterbalanced by the presence of dense amblyopia and a prevailing cultural disinclination towards the wearing of spectacles.

\section{Recommendations}

Given these findings there are several measures that need to be instigated to address the obvious visual needs of these children. Provision of low vision aids for those with the potential for reading vision would be highly desirable. A single-handed low visual aid technician could cover all the blind schools once a year and assess and provide appropriate aids. Refractive and optometric services also need to be more widely available - a situation that is only likely to occur with progress in economic development. Cataract screening and referral of infants need to be performed at the earliest possible stage by obstetricians and paediatricians. With a birth rate of 33.7 per 1000 per year, a population of 23 million and a prevalence of blinding cataract close to 2.5 per 10000 children, it may be calculated that there are approximately 200 new cases of blinding childhood cataract per annum throughout the country. The Tashkent Medical Paediatric Institute and Mercy Project are creating a single well-equipped tertiary referral centre in the capital to handle most of these cases. A system is envisaged in which two or three times a year a batch of children will undergo surgery, receive appropriate refractive correction and return to their towns and villages. Itinerant follow-up will then occur at peripheral hospitals and clinics, during which visits new cases will be assessed for referral to Tashkent for the next surgical session. Glaucoma accounted for approximately $5 \%$ of the preventable visual loss in this study. The routine use of antimetabolite-enhanced drainage surgery is under consideration.

To address the issue of bias, further work needs to be done on the nature of visual handicap among the children at the schools for multiple disability and a more complete survey of the area around the Aral Sea.

N.K.R. gratefully acknowledges sponsorship from the following sources: Central Sheffield University Hospitals NHS Trust; Christoffel-Blindenmission Childhood Blindness Research Account, University College London; Lister Travelling Fellowship, Royal College of Ophthalmologists, UK; Royal Society of Medicine Travel Fellowship; Children's Eye Study Group (UK) Travel Fellowship; The Newby Trust; Chiron Pharmaceuticals Ltd; Chauvin Pharmaceuticals Ltd; Clement Clark Ltd; Keeler Ltd; Dr Solomon Software Ltd; Mercy Project Uzbekistan. We are grateful for the cooperation of the Department of Health and the Department of People's Education of the Republic of Uzbekistan. This study could not have occurred without the assistance of medical staff, translators and administrators of the Tashkent Medical Paediatric Institute and Mercy Project. The data base and statistical programmes were written by E. der Kureghian, BA, MIM, PhD.

\section{References}

1. World Health Organization. Prevention of childhood blindness. Geneva: WHO, 1992.

2. Foster A, Gilbert CE. Epidemiology of childhood blindness. Eye 1992;6:173-6.

3. Elder MJ, De Cock R. Childhood blindness in the West Bank and Gaza Strip: prevalence, aetiology and hereditary factors. Eye 1993;7:580-3.

4. Eckstein MB, Foster A, Gilbert CE. Causes of childhood blindness in Sri Lanka: results from children attending six schools for the blind. Br J Ophthalmol 1995;79:633-6.

5. Rahi JS, Sripathi S, Gilbert CE, Foster A. Childhood blindness in India: causes in 1318 blind school students in nine States. Eye 1995;9:545-50.

6. Gilbert CE, Canovas R, Hagan M, Rao S, Foster A. Causes of childhood blindness: results from West Africa, South India and Chile. Eye 1993;7:184-8.

7. Gilbert CE, Foster A. Causes of blindness in children attending four schools for the blind in Thailand and the Philippines. Int Ophthalmol 1993;17:229-34.

8. Khalmetov RK, Beketova LM. Health status of children and adolescents in the main cotton growing region of Central Asia. Vestnik Rossiiskoi Akademii Meditsinskikh Nauk 1993;6:43-6.

9. Mukhamedov TM, Iampolskaia IA, Fedoseev V, Asatullaev SA, Kattaev SK, Subbota IA. Physical development of children and adolescents in Uzbekistan: Gigiena I Sanitariia 1994;4:44-6. 
10. Pisarevsky SL. Nosological structure of blindness and poor vision in the children of Uzbekistan: its causes and progress observed over a long period and some methods of medical rehabilitation [PhD thesis]. Moscow: Russian Ministry of Health, Ocular Research Institute, 1990.

11. Jay B. Causes of blindness in schoolchildren. BMJ 1987;291:1183-4.

12. Faizullaev IK. Independent Uzbekistan today. Tashkent, Uzbekistan, 1993.

13. Thylefors B, Negrel AD, Pararajesegaram R, Dadzie KY. Available data on blindness. Ophthalmic Epidemiol 1995;2:5-39.

14. Kia I, Weinstein KI. Uzbekistan: demographic and health survey (1996). Macro International, 1996.

15. Gilbert C, Foster A, Negrel A, Thylefors B. Childhood blindness: a new form for recording causes of visual loss in children. Bull World Health Organisation 1993;71:485-9.
16. Elston JS, Timms C. Clinical evidence for the onset of the sensitive period in infancy. Br J Ophthalmol 1992;76:327-8.

17. Lambert SR, Drack AV. Infantile cataracts. Surv Ophthalmol 1996;40:427-58.

18. Potter WS. Pediatric cataracts. Pediatr Clin North Am 1993;40:841-53.

19. Tucker S, Jones B, Collin R. Systemic anomalies in 77 patients with congenital anophthalmos or microphthalmos. Eye 1996;10:310-4.

20. Elder MJ. Aetiology of severe visual impairment and blindness in microphthalmos. Br J Ophthalmol 1994;78:332-4.

21. Kallen B, Robert E, Harris J. The descriptive epidemiology of anophthalmia and microphthalmia. Int J Epidemiol 1996;25:1009-16. 